\title{
An ISM Based Approach for Product Innovation Using a Synthesized Process
}

\author{
Ming-Tang Wang, ${ }^{1}$ Chang-Tzuoh Wu, ${ }^{1}$ Rain Chen, ${ }^{2}$ Wen-Liang Chen, ${ }^{3}$ and Chien-Yu Liu ${ }^{1}$ \\ ${ }^{1}$ Department of Industrial Design, National Kaohsiung Normal University, Kaohsiung 824, Taiwan \\ ${ }^{2}$ Department of Creative Product Design, Southern Taiwan University of Science and Technology, Tainan 710, Taiwan \\ ${ }^{3}$ Department of Product Design, Shu-Te University, Kaohsiung 824, Taiwan
}

Correspondence should be addressed to Ming-Tang Wang; mtwang2000@gmail.com

Received 2 July 2014; Accepted 13 August 2014; Published 14 September 2014

Academic Editor: Stephen D. Prior

Copyright (C) 2014 Ming-Tang Wang et al. This is an open access article distributed under the Creative Commons Attribution License, which permits unrestricted use, distribution, and reproduction in any medium, provided the original work is properly cited.

\begin{abstract}
Internet shopping has become a global business activity; it also increases the workload of delivery services. The Transnet logistics can easily deliver and collect cargos from everywhere, with difficulty of having the greatest efficiency. This study is composed of four parts; the first step of identifies opportunities in which proposing an auxiliary vehicle for Transnet truck to support service in narrow or crowded road. A weight calculation system determined the relative value of different items and applied the interpretive structural model (ISM) to modularize SET for constructing innovation from integrated new product development (iNPD). From finding GAPs in opportunities of search results are explored an innovative light electric carrier as an auxiliary vehicle is determined. The second part consists of quantifying 21 items based upon 7 specific attributes for user orientation. The third part describes a new kind of light electric vehicle which is developed and mounted on the rear side of transport trucks; it can be used to deliver goods along narrow roads. Finally, more specific details of a collapsible electric motor carrier with a battery that is recharged using truck's power system after using it are presented. The results of this study establish a research and product design to help Transnet drivers by improving carrying efficiency in narrow and crowded roads.
\end{abstract}

\section{Introduction}

Nowadays it has become very popular to shop online rather than face-to-face in real stores. The Mainland China site "Taobao net" claims to have a huge business channel from which you can buy anything you want. Although virtual transactions can be made on the internet, the distribution of goods still requires a physical delivery method. Therefore, logistical and distribution industries need to change their systems so as to satisfy the needs of online shoppers. The development of the Transnet service has been a step forward, but it still must improve if it wants to be the most diverse and convenient method. In 1976, the main company of Transnet service, "Takkyubin (Transnet)," evolved from a standard home delivery system. It was pioneered by Daiwa transportation in Japan, and its main business feature is that one can call in and then immediately have goods, even small goods; shipping begins to a specified location for delivery on the next day. In late 2000, this system was first introduced by "TECO" and the "President Group" into Taiwan. Popular carriers such as "Taiwan Pelican" and "President Transnet Corp" vigorously promote the domestic Transnet market through the mass media by whipping up big waves of consumption behavior because the business model is convenient for consumers.

Transnet services gradually expanded into many related peripheral businesses. They quickly transport frozen and perishable cargos, among others, to and from places like convenience stores, using systems like cash on delivery and credit card payment. It has steadily become a more flexible and diverse service, filling a niche in consumption needs. Although this diverse delivery service seems to have a complicated distribution approach, it can deal with a variety of business logistics, although it still needs to improve. Delivering goods anywhere as quickly as possible is an essential requirement for an online business. Each of the goods must reach the consumer's hands in the most effortless 


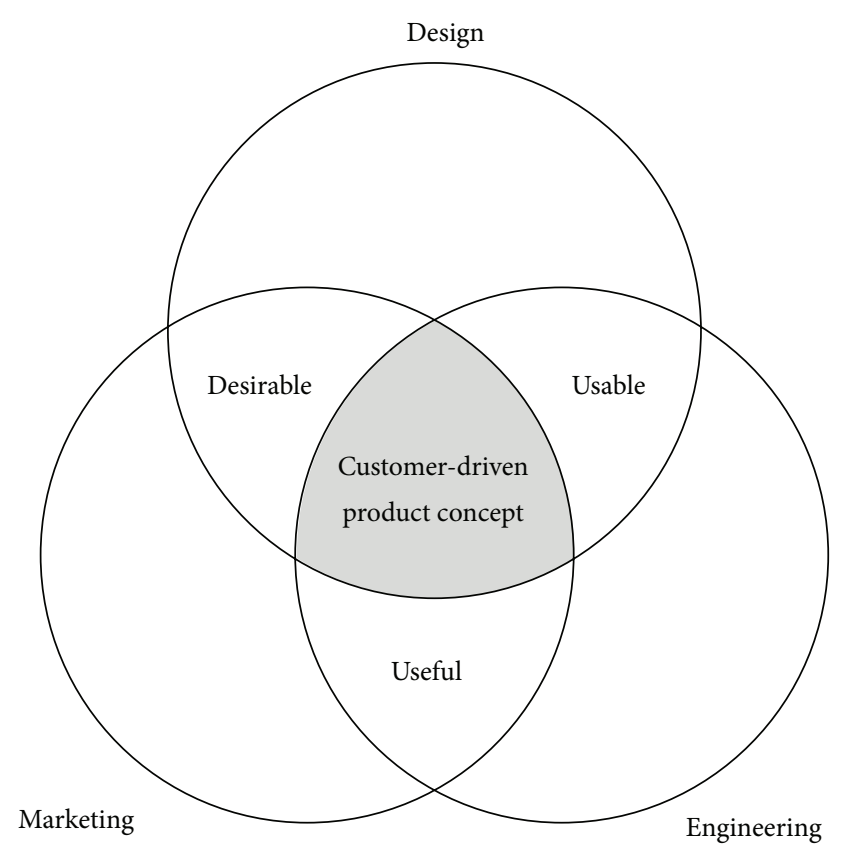

Figure 1: Overlap of disciplines leads to value of user centered [1].

way, reducing energy and unnecessary waste. This needs to be a primary goal of the industry.

Existing delivery vehicles are mostly large and heavy, preventing delivery to some areas. Therefore, there is a need for a supplementary transportation device, such as a scooter, to collect or send goods to scattered customers' locations in the city. There is still no solution for enabling Transnet services to reach some of the more difficult to reach locations, which means that there is a need for an innovative product or mechanism to solve this problem.

Figure 1 shows that an integrated product innovation process (iNPD) requires the combination of three areas: market research, engineering and product design, and new product development. It is not just a set of methods that can be plugged into an existing company structure. It is a way of thinking that combines three key elements: (1) a truly horizontal and interdisciplinary structure, (2) a commitment to maintain a focus on what customers and other stakeholders value, and (3) a system that begins with an emphasis on qualitative methods of discovery and development and evolves toward quantitative methods of real methods of refinement and manufacture. It is a good way to transfer and combine the marketing research, engineering, and design of products to explore the complex and comprehensive research $[1,2]$. Finally, the process of iNPD can be explored for complex innovative issues, converting an excursive hypothesis into a specific proposal and combining multifaceted fields in a concise approachable way which puts lessons learned from a project-based approach into a form for teaching new cognitive product development to multidisciplinary student teams [3]. A proposal has been made to create green Wi-Fi equipment to communicate regarding outdoor activities from
iNPD [4]. There has been an investigation into developing a highly rational industrial design using the iNPD process of high-tech industrialization by two actual projects through the use of these methods [5].

\section{Outline of the Research Model Development Procedure}

This synthesized process creates a combination of design and analysis to construct a product innovation procedure. Figure 1 shows that the overlap in disciplines of design, engineering, and marketing leads to value of user centered which define the usability, usefulness, and desirability of the product to the customer, the value that also leads to success in the market and profit for the company. Figure 2 shows that there are four phases in this iNPD flow chart: (1) identifying opportunities, (2) understanding opportunities, (3) conceptualizing opportunities, and (4) realizing opportunities [4, 6-8]. We believe that using this combination for product innovation will produce better solution.

The basic procedure of iNPD has processed an example of a product hybrid that successfully filled a gap was the first Apple iMac. Integrating the monitor and CPU, using translucent plastic combined with a variety of bright candy colors, made the iMac easier and more fun to use than other computers. The iMac evolved with and continued to define the aesthetics of offices and homes, which look sharp with an iMac on the desk. Setup was a breeze, and cable-management issues virtually disappeared. The Apple desktop has continued to use the integration concept and is now an elegant thin, soft-cornered rectangle with a minimal aluminum base [1], It is found that this result has got a usable, useful, and desirable product for customer.

2.1. Identifying Opportunities. There are three phases in this stage.

(1) Selecting and Evaluating SET Factors. This phase introduces a way to collect market information from the essential SET factors (social change: social and cultural trends and drivers, reviving historical trends; economic trends: state of economy, shift in focus on where to spend money, level of disposable income, and technological innovation: stateof-the-art and emerging technology, revaluating existing technology) for locating a better position from which to plan an innovative opportunity. According to research, users' age is related to average daily use of the internet in general and use of the internet for information access [9]. In order to collect the factors of all issues of SET, this study uses eight participants whose ages are from 20 to 24 for brainstorming; two participants are graduate students, other two are industrial designers, and other four are the related company drivers. In order to evaluate each SET item, a weighted formula is used to calculate the average value of a particular set of numbers with different levels of relevance. The relevance of each number is called its weight, which is represented as a percentage of the total relevancy. Firstly, each weighted item is given a value 


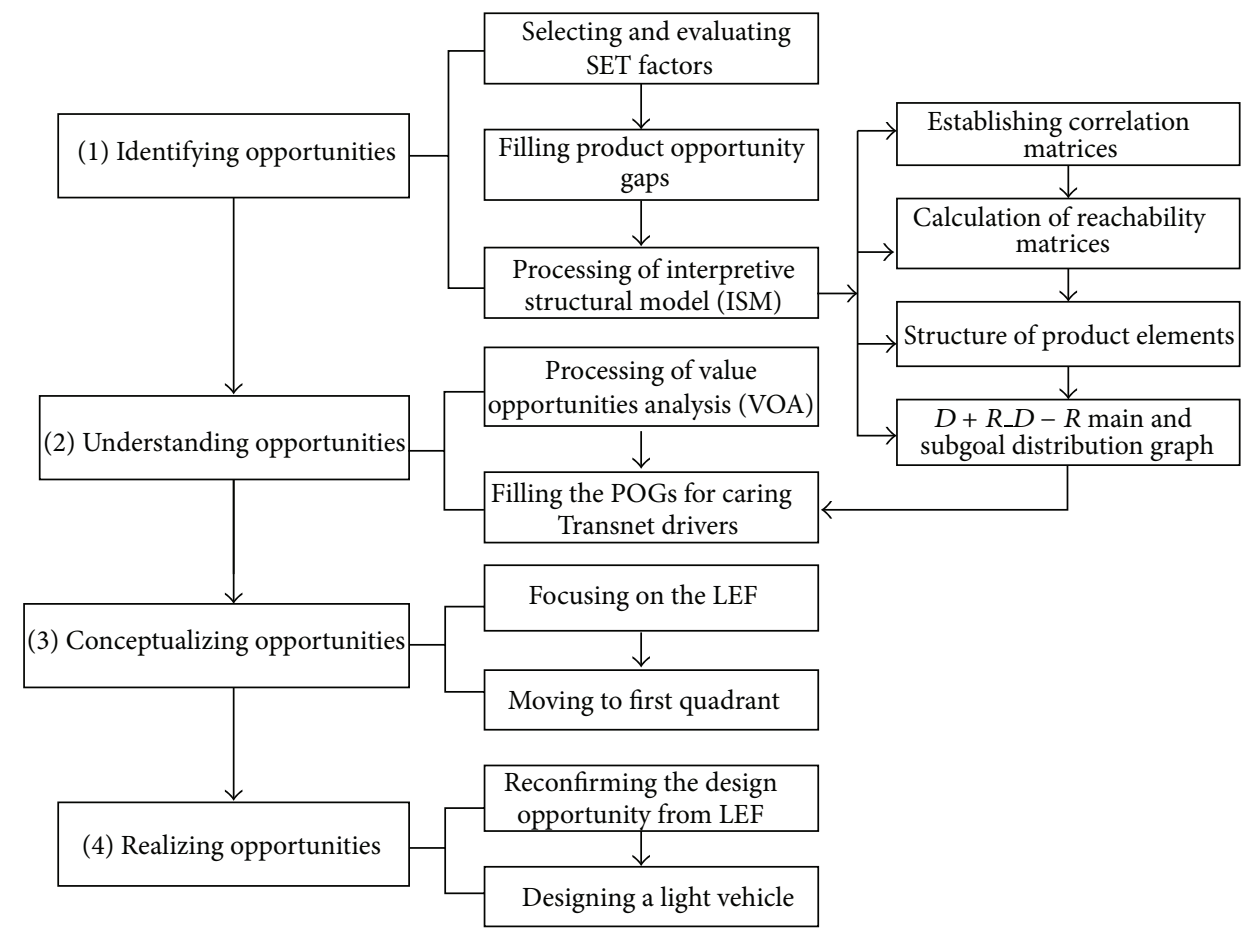

Figure 2: Flow chart of research and design for Transnet industry.

TABLE 1: The high value elements from weighted calculation.

\begin{tabular}{|c|c|c|c|c|c|c|c|c|c|c|c|c|c|c|}
\hline \multicolumn{5}{|c|}{ S (social change) } & \multicolumn{5}{|c|}{ E (economic trend) } & \multicolumn{5}{|c|}{ T (technology innovation) } \\
\hline & Elements & $x$ & $w$ & Scores & & Elements & $x$ & $w$ & Scores & & Elements & $x$ & $w$ & Scores \\
\hline 1 & Virtual community & 6 & 2 & 12 & 1 & Cargo variety & 4 & 2 & 8 & 1 & $\begin{array}{l}\text { Replace the internal } \\
\text { combustion engine }\end{array}$ & 2 & 1 & 2 \\
\hline 2 & Otaku culture & 5 & 4 & 20 & 2 & $\begin{array}{l}\text { Services } \\
\text { commercialization }\end{array}$ & 5 & 5 & 25 & 2 & Mobile network & 5 & 5 & 25 \\
\hline 3 & Fashion pursuit & 3 & 2 & 6 & 3 & Virtual currency & 4 & 4 & 16 & 3 & Cloud technology & 5 & 4 & 20 \\
\hline 4 & Logistics service & 5 & 5 & 25 & 4 & Energy price rising & 4 & 3 & 12 & 4 & Electric vehicles & 3 & 5 & 15 \\
\hline 5 & $\begin{array}{l}\text { Popularity of } \\
\text { internet }\end{array}$ & 5 & 1 & 5 & 5 & $\begin{array}{l}\text { Working hours } \\
\text { increasing }\end{array}$ & 2 & 1 & 2 & 5 & Energy-saving & 1 & 5 & 5 \\
\hline 6 & Internet shopping & 6 & 4 & 24 & 6 & Parity of $3 \mathrm{C}$ products & 3 & 3 & 9 & & & & & \\
\hline 7 & $\begin{array}{l}\text { Convenience store } \\
\text { services }\end{array}$ & 4 & 3 & 12 & & & & & & & & & & \\
\hline
\end{tabular}

from 1 to 5 ( $w=$ relative weight) by researchers, as shown in Table 1; the " 5 " is the most relative to researching topic, gradually reducing number that it represents to decrease the correlation with topic; the weight value is decided by discussion with all participants. This can be seen by the drawn related line between each item of SET; all related lines also have been decided by all participants. Finally, the weighted $\operatorname{Avg}_{x}$ is used in formula (1), and the weighted results are shown in Table 1 . The greater values of weighted Avg can be used to construct POGs (product opportunity gaps), which are then generalized into fuzzy idea of opportunity. The brain storming and drawing related lines concluded the high scores to build opportunity gaps on qualitative and quantitative methods. The SET factors can identify POGs for a targeted user group. Consider the following:

$$
\begin{aligned}
& \text { weighted } \operatorname{Avg}_{x}=w_{1} x_{1}+w_{2} x_{2}, \ldots, w_{n} x_{n} \\
& w=\text { relative weight }(1 \sim 5) \\
& x=\text { value. }
\end{aligned}
$$

(2) Filling Product Opportunity Gaps. Identifying product opportunities should be the core force driving the companies that manufacture products, supply services, and process information. A product opportunity exists when there is a gap between what is currently on the market and the possibility 


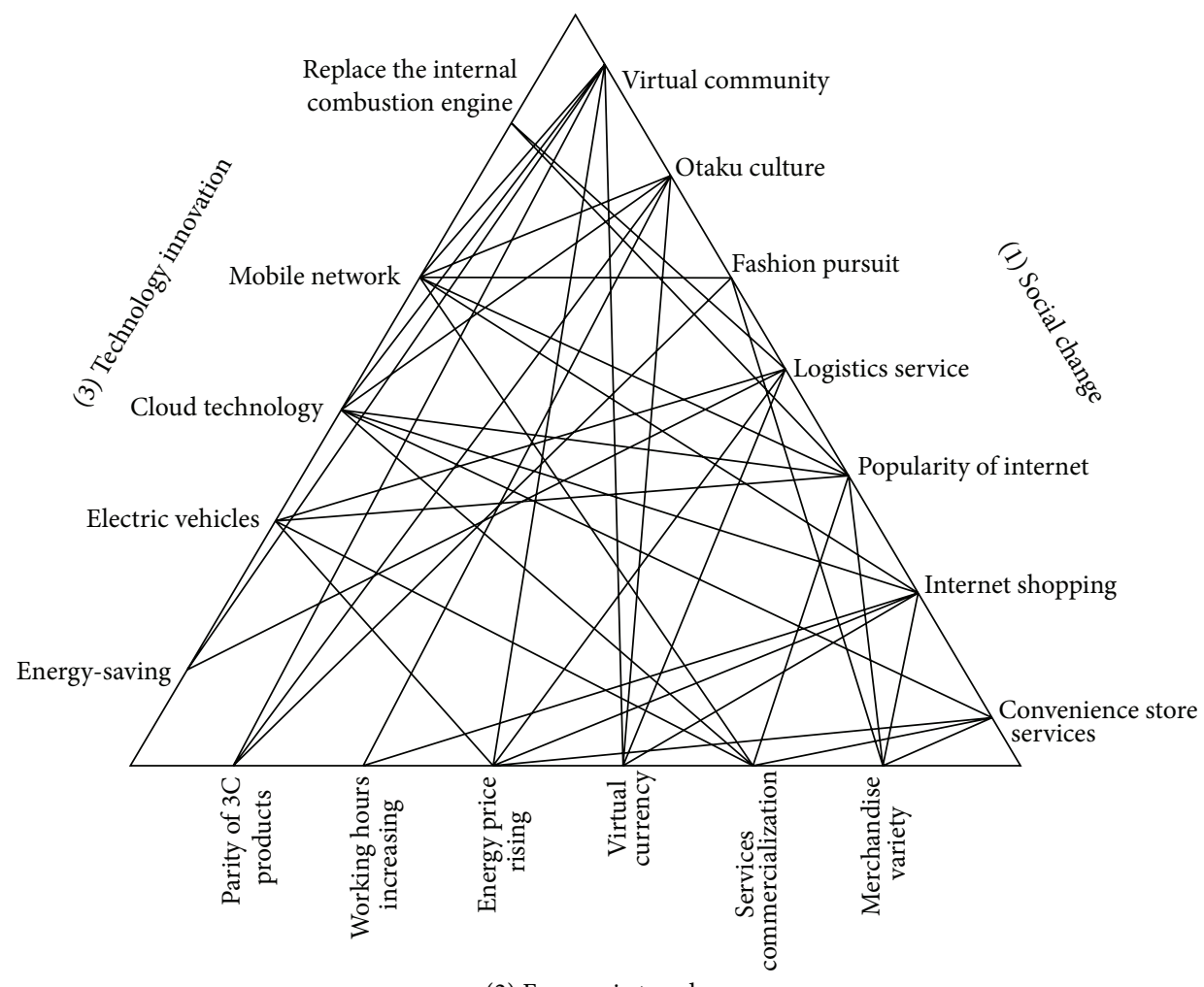

(2) Economic trend

FIGURE 3: The gaps concluded from all connections between each SET item.

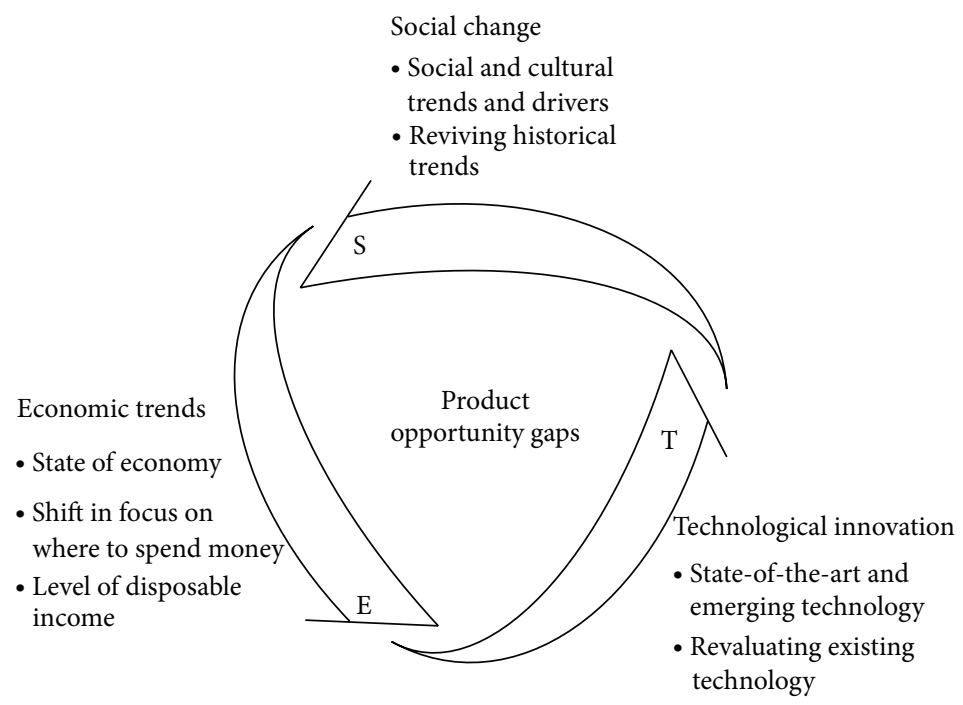

FIGURE 4: Scanning SET factors leads to POGs [1].

for new or significantly improved products that result from emerging trend. Figure 4 shows a product that successfully fills product opportunity gaps (POGs) when it meets the conscious and unconscious expectations of customers and is perceived as useful, useable, and desirable $[1,2]$.

(3) Processing Interpretive Structural Model (ISM). Generally speaking, when people study complex and divisive issues and conduct problem analysis and needs assessments, they usually make intuitive judgments based on prior experience rather than rationally assessing the situation. Therefore, they need more effective methods, such as ISM, DEMATEL (Decision-Making Trial Evaluation Laboratory), and the KJ method, which are used for ideal planning [10]. ISM is an especially effective method because all elements can be processed with a simple matrix. Interpretive structural 
modeling (ISM) is a system proposed and developed by Warfield, starting from 1973 [11-14]. It is often used to provide fundamental understanding of complex situations and to put together a course of action for solving a problem. The mathematical foundations of the methodology can be found in various reference works [15].

The philosophical basis for the development of the ISM approach is presented in Warfield $[11,12]$, and the conceptual and analytical details of the ISM process were later outlined in greater detail [12-14]. Interpretive structural modelling (ISM) is a well-established methodology for identifying relationships among specific items. It is useful for defining a specific problem or an issue $[16,17]$. It is a suitable modeling technique for analyzing the influence of one variable on other variables [18], which helps groups of people in structuring their collective knowledge [19]. It is used here to refer to the systematic application of some elementary notions of graph theory in such a way that theoretical, conceptual, and computational leverage are efficiently exploited to construct a graph $[19,20]$.

One simple way to describe the relation of the 8 categories within the matrix in this case is to assign weights $w_{i}$ for the $i$ th element according to its relative position in an individual hierarchy. By summing up the individuals, a collective score $w_{i j}$ can be assigned to each element, which can then be used to construct a matrix $[A]$ to present the related relationship of each element. Consider the following:

$$
\begin{gathered}
{[A]=\sum_{j=1}^{n_{j}} w_{i j},} \\
{[A]=\left[\begin{array}{ccc}
w_{11} & \cdots & w_{i 1} \\
\vdots & \ddots & \vdots \\
w_{1 j} & \cdots & w_{i j}
\end{array}\right] .}
\end{gathered}
$$

Malone [20] terms this the adjacency matrix of $D$, which is constructed by setting $a_{i j}=1$, wherever there is an $\operatorname{arc}$ in $D$ directed from element $s_{i}$ to element $s_{j}$, and by setting $a_{i j}=0$ elsewhere. Element $s_{j}$ is said to be reachable from element $s_{i}$ if a path can be traced on $D$ from $s_{i}$ to $s_{j}$. By convention, an element $s_{i}$ is said to be reachable from itself by a path of length 0 . The reachability matrix $M$ of a digraph is defined as a binary matrix in which the entries $m_{i j}$ are 1 if element $s_{j}$ is reachable from element $s_{i}$; otherwise $m_{i j}=0$. It can be shown that the reachability matrix may be obtained operationally from the adjacency matrix by adding the identity matrix and then raising the resulting matrix to successive powers until no new entries are obtained. That is,

$$
[M]=([A]+[I])^{n},
$$

where $n$ is determined such that

$$
([A]+[I])^{n-1}<([A]+[I])^{n}=([A]+[I])^{n+1} .
$$

Some articles published recently on decision making [21, 22], design planning [23-25], productivity issues [26], and so forth have provided the adequate ground to begin with.
2.2. Understanding Opportunities. To create a breakthrough product, we must know who our customer is and how to place that knowledge in the perspective of marketing our product competitively. In order to understand the possible opportunity of POGs of SET from the first phase, we must continue to verify the opportunity for possible products. As awareness begins to grow, the team produces models of the experience and starts to develop an understanding of the value opportunities for the product. From this, the factors of importance that will make the product useful, usable, and desirable start to emerge. There are seven composite attributes: emotion, ergonomics, aesthetics, identity, impact, core technology, and quality, which are each surveyed for the possible design direction. These attributes are divided into twenty-two value opportunities to process value opportunities analysis (VOA) and to make clear descriptions of POGs through a quantitative survey. There are four steps that can be divided into two phases. (1) Processing of value opportunities analysis (VOA): (A) value opportunities modification: increase or decrease the numbers of value opportunities to fit a fuzzy product idea. (B) Quantitative surveys identify the significant values that have a semantic survey of products from the questionnaire based on 10 segments of a Likert scale. (C) Recognize the importance of value opportunities: when the average scores of descriptive statistics of VOA are less than 4, the importance is deemed as "low." A level of 4 to 8 is deemed as "moderate" requirements, and more than 8 is deemed as "high." Some higher important value opportunities will be focused upon to describe related design concepts. (2) Filling the POGs for caring Transnet drivers to find the fuzzy front end: the high important ones and POGs are integrated as the directions for conceptualizing ideas which can be used as opportunities.

2.3. Conceptualizing Opportunities. In this phase, pictures simulate the preferred orientation of significant value opportunities for target groups which (1) focusing on the LEF (lifestyle, ergonomics, and feature). The user life-style is used to conceptualize the product design direction; integration of style and technology is used to orient an approach from the standpoint of users and is centered on caring for humans and the earth. (2) Moving to the right and upper quadrant we see idea opportunities which must move to a high value quadrant of style, tech, and other values, positioned appropriately for an anticipated product.

2.4. Realizing Opportunities. In order to realize opportunities in this phase, the designer must insist on focusing on an idea opportunity to decrease manpower on Transnet popularity. The proposal will be presented by sketching the concept as a product design. The "care" is a state of mental suffering or of engrossment: to care is to be in a burden mental state, one of anxiety, fear, or solicitude about something or someone [27]. To make effort to do something correctly, safely, or without causing damage. The care and design has been constructed as a design issue; it seems to begin from green design, considering humans and the environment to combine motivation [28]. In fact, it can let the design get a 


$$
\begin{gathered}
1 \\
2 \\
3 \\
3 \\
5 \\
5 \\
7 \\
7 \\
7 \\
8
\end{gathered}\left[\begin{array}{llllllll}
0 & 1 & 0 & 0 & 0 & 0 & 0 & 1 \\
1 & 0 & 1 & 0 & 0 & 0 & 0 & 0 \\
0 & 1 & 0 & 0 & 0 & 0 & 0 & 0 \\
1 & 0 & 0 & 0 & 0 & 0 & 0 & 0 \\
0 & 0 & 1 & 0 & 0 & 0 & 0 & 0 \\
0 & 1 & 0 & 0 & 0 & 0 & 0 & 0 \\
0 & 0 & 0 & 0 & 0 & 1 & 0 & 0 \\
1 & 0 & 0 & 0 & 0 & 0 & 0 & 0
\end{array}\right]
$$

(a) Original incidence matrix $[A]$

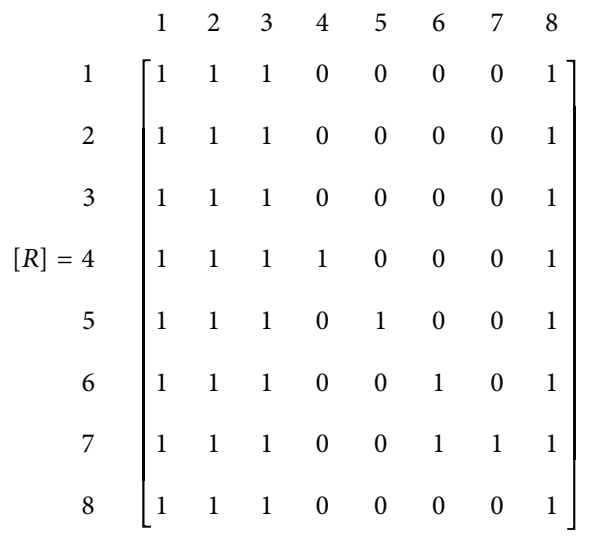

(b) Reachability matrix $[R]$

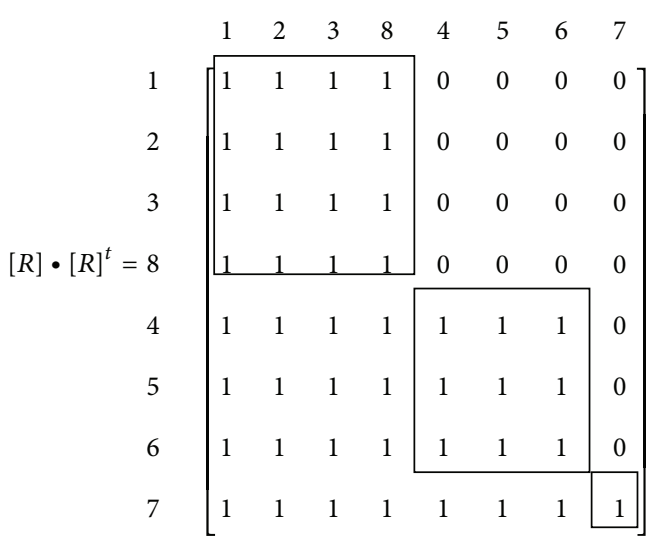

(c) Rearranged matrix and retrieval of clusters

Figure 5: Step by step of ISM from (a) to (c).

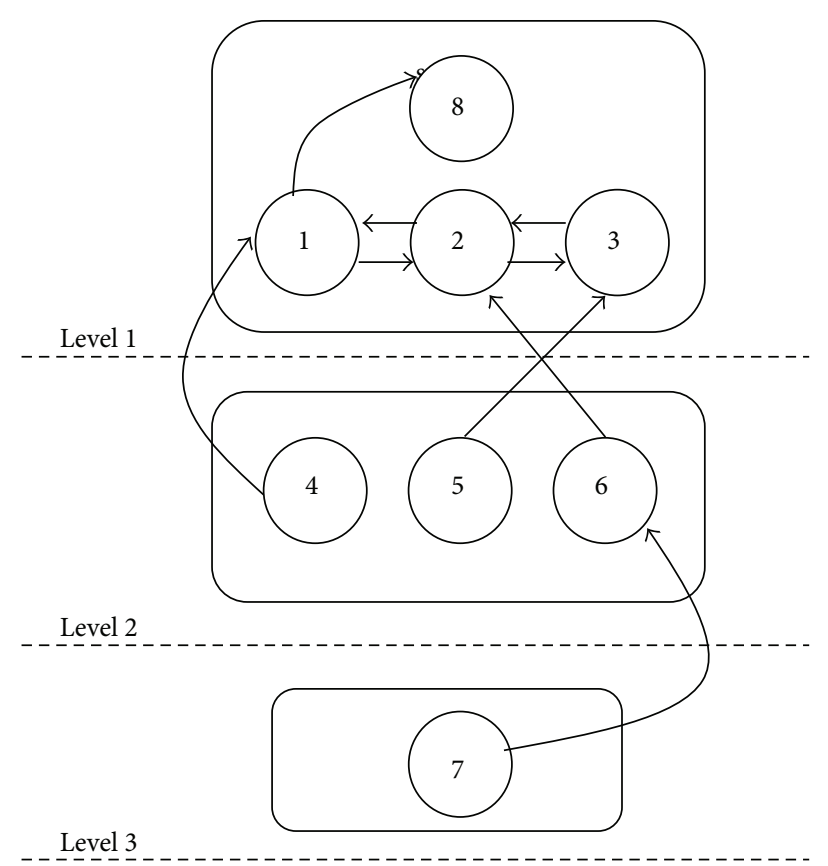

FIgURE 6: Hierarchical interaction graph of the system. 
chance to be reinforced to fit for living creatures; this design concept can be constructed between carers and by-carers to improve product value and create valuable issues for common topics.

\section{Result}

After the above mentioned iNPD process, the results can be determined from those four phases, they also have been explained as below description.

3.1. Identifying Opportunities. In order to construct product opportunity gaps (POGs), we have valuated SET and used ISM as effective method for ideal planning.

3.1.1. High Weighted Value. In order to recognize the value of the opportunity, we selected six people to serve as focus group members to discuss the topic of Transnet from three major related categories: social change, economic trends, and technological innovation. Figure 3 shows all related lines that also have been decided by all participants. Analysis of the discussion results gave us seven social change items, six economic trends items, and five technological innovation items (Table 1). The number of " $x$ " is the connection of an item with items from other categories, the " $w$ " is the relative weight (1-5) of each item, and, finally, the "weight value" is the score of " $x$ " multiplied by " $w$ ", as in formula (1), which means that we can select the higher importance weight of SET evaluation as samples for ISM. Following the completion of this process, the high scores on behalf of this evaluation have a high value opportunities possibility. All project details are shown in Table 1 . The selected high score items from the SET weighted matrix evaluation left us with eight categories: (1) social changes: logistics services (25), internet shopping (24), and Otaku culture (20); (2) economic trends: services commercialization (25) and virtual currency (16); (3) technology innovation: mobile network (25), cloud technology (20), and electric vehicles (15).

3.1.2. Filling Product Opportunity Gaps. The high score items, from the SET weighted matrix evaluation, left us to find a GAP. Figure 4 shows that the value of identifying opportunity is based on experience and discussion to identify the fuzzy front end of the opportunity; we can find a customer-driven product design to use a carrier located on large transport vehicles, it can provide better caring for one person driving in Transnet service.

3.1.3. Processing of the Interpretive Structural Model. Based on the correlation between elements in a system, customer need assessments are conducted using matrix arithmetic. Directional hierarchical relationship graphics have been generated to formulate execution policies and develop problem-solving strategies. Interpretive structural model (ISM) can compute a model to show our thinking processes in order to deconstruct problems for this study. A few follow the procedure which Hsiao et al. [25] proposed for ISM, illustrated below.
(1) Construct a correlation matrix: to conduct logical operations and analyze the resulting hierarchical structures, we must arrange the high weight value elements (entries) of SET in the form of a matrix to select and sample the structure elements and compare the relationships between the elements of SET (Table 1). To compare the relationships, a directional correlation matrix [A] (formula (2)) is formed using the relationship $\left(a_{i j}\right)$ (formula (3)) between one element and another. Figure 5(a) represents the incidence matrix (original matrix) of an example system containing eight components and displays the incidence relationships. (2) Generate a reachability matrix: the reachability matrix $[R]$ (from formulas (4) and (5)) is deducted from the incidence matrix $[A]$ if a Boolean $n$-multiple product of $[A]+[I]$ uniquely converges to $R$ for all integers $n>n_{0}$, where $n_{0}$ is an appropriate positive integer, $[I]$ is a Boolean unity matrix, and + is an addition in the Boolean sense [29]. Matrix $[R]$ represents all direct and indirect linkages between components. Relation transitivity is a basic assumption in ISM. Figure 5(b) represents the reachability matrix $[R]$ derived from matrix $[A]$, in which an entry $r_{i j}=1$ if component $j$ is reachable by $i$, although the path length may be one or more. "Reachability" in graph theory is the ability to move from one vertex in a directed graph to some other vertices (formula (4)). This is sufficient to find the connected components in the graph. (3) Generate a rearranged matrix: cluster elements that affect one another in the output matrix of the reachability matrix. Figure 5(c) reveals three clusters in the system, namely, $\{1,2,3,8\},\{4,5,6\}$, and $\{7\}$, and the clustered components are integrated and treated as a single entity. (4) Illustrate the hierarchical relationships of elements: the hierarchy graph is then obtained by identifying a set of components in matrix $[R]$ that cannot reach or be reached by other components outside the set itself. The oriented links then connect the nodes from source to sink based on the incidence matrix. Notably, the rounded rectangles in Figure 6 indicate clusters within the retrieved group, in which the information flow forms a loop. In this step, the elements' hierarchical relationships are illustrated according to the rearranged matrix, providing decision makers with the procedures and hierarchical structures to use in the deconstruction of a problem. (5) Draw the $D+R \_D-R$ element distribution graph: based upon the reachability matrix $[R]$, the user must add up the scores of the elements in each row to generate $D$ and the elements in each column to generate $R$. After this, calculate the values of $D+R$ and $D-R$ to generate a reachability matrix determinant (see Table 2 ) and then demonstrate $D+R \_D-R$ on a binary scale to interpret both the problem and the target areas. This system can also be employed to analyze independent elements according to their hierarchical relationships. After the element level has been determined, draw the $D+R \_D-R$ element distribution graph to find out the main problem and main target (see Figure 7). Once this has been accomplished, the power-driven and easy to use vehicles can be loaded on a large vehicle which can provide better quality of Transnet for driver from ISM process. This analysis can make the selected SET topics to 
TABLE $2: D+R \perp D-R$ and reachability matrix determinant.

\begin{tabular}{cccccccccccc}
\hline & 1 & 2 & 3 & 4 & 5 & 6 & 7 & 7 & $D$ & $D+R$ & $D-R$ \\
\hline 1 & 1 & 0 & 0 & 1 & 0 & 0 & 0 & 0 & 2 & 6 & -2 \\
2 & 1 & 1 & 1 & 1 & 0 & 0 & 0 & 0 & 4 & 6 & 2 \\
3 & 1 & 1 & 1 & 1 & 0 & 0 & 0 & 0 & 4 & 6 & 2 \\
4 & 1 & 0 & 0 & 1 & 0 & 0 & 0 & 0 & 2 & 6 & -2 \\
5 & 0 & 0 & 0 & 0 & 1 & 1 & 0 & 0 & 2 & 3 & 1 \\
6 & 0 & 0 & 0 & 0 & 0 & 1 & 0 & 0 & 1 & 4 & -2 \\
7 & 0 & 0 & 0 & 0 & 0 & 1 & 1 & 0 & 2 & 3 & 1 \\
8 & 0 & 0 & 0 & 0 & 0 & 0 & 0 & 1 & 1 & 2 & 0 \\
$R$ & 4 & 2 & 2 & 4 & 1 & 3 & 1 & 1 & & & \\
\hline
\end{tabular}

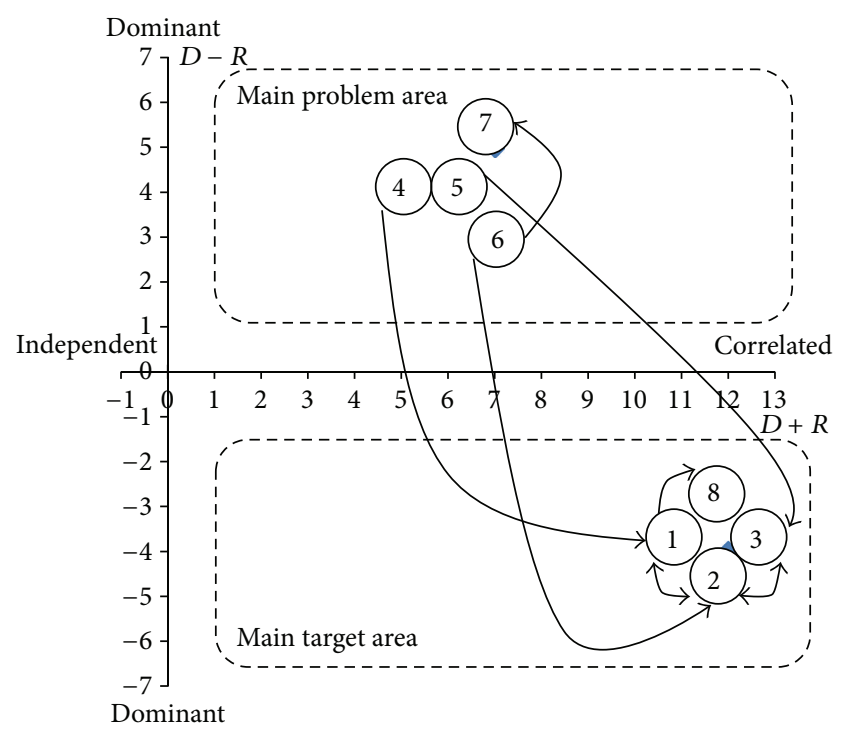

Figure 7: $D+R \_D-R$ element distribution graph.

understand their relationships, determined what is the main problem or main target, and connection lines clarify their relation directions to recognize all topics.

3.2. Understanding Opportunities. Value opportunities (VO) of proposed direction can be classified into specific attributes that contribute to the usefulness, usability, and desirability of a product, connecting the features of the target product to evaluate those values from specific attributes. There are seven attributes: emotion, ergonomic, aesthetic, identity, impact, core tech, and quality.

3.2.1. Processing of Value Opportunities Analysis (VOA). First, the original opportunities of the attribute must be modified to fit the real user needs, and each of the seven attributes must contribute to the overall experience of the product. In doing this, the 22 original value opportunities will be adjusted to 21 items. Of these 21 items, 6 have emotional attributes, 2 have ergonomic attributes, 4 have aesthetic attributes, 3 have identity attributes, 2 have impact attributes, 2 are related to core technology attributes, and 2 are related to quality attributes. Then, to process the quantitative survey section

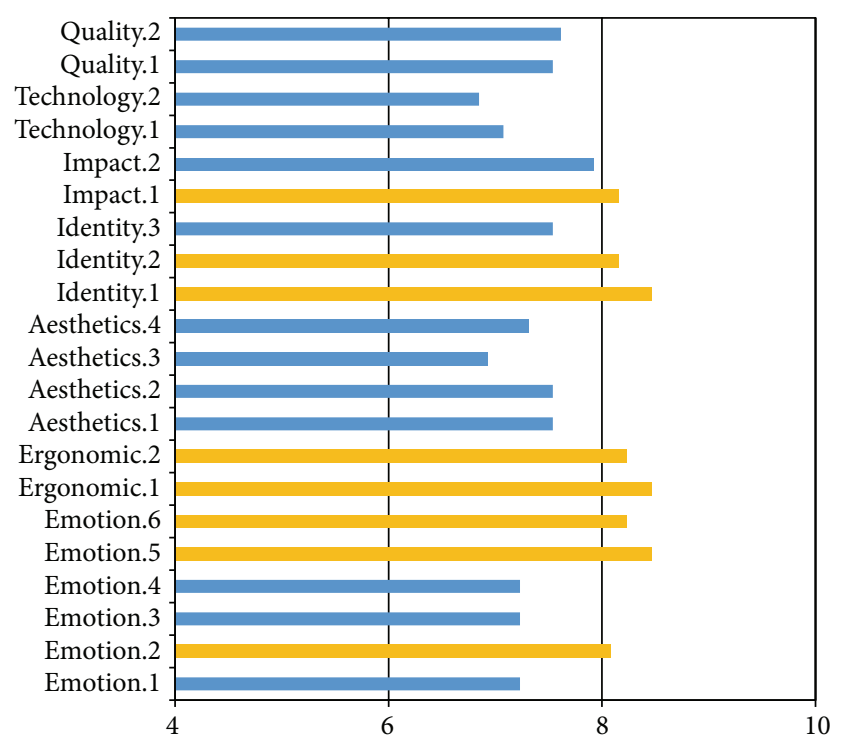

FIGURE 8: The scores of value opportunity analysis (VOA).

TABle 3: The fuzzy front end of creative design for caring Transnet drivers.

\begin{tabular}{lll}
\hline LEF & Collected factors & Design directions \\
\hline Life style & $\begin{array}{l}\text { Confidence } \\
\text { Sense of place } \\
\text { Reputation } \\
\text { Social } \\
\text { Environment }\end{array}$ & $\begin{array}{l}\text { Transnet truck needs to pass } \\
\text { the narrow streets or alleys }\end{array}$ \\
\hline Ergonomics & $\begin{array}{l}\text { Comfort } \\
\text { Security } \\
\text { Point in time }\end{array}$ & $\begin{array}{l}\text { Easy to drive and needs to be } \\
\text { able to charge at any time }\end{array}$ \\
\hline \multirow{2}{*}{ Feature } & $\begin{array}{l}\text { Point in time } \\
\text { Sense of place } \\
\text { Independence }\end{array}$ & $\begin{array}{l}\text { Foldable, easy to carry cargo, } \\
\text { small electric vehicles }\end{array}$ \\
\hline
\end{tabular}

of the questionnaire, the question items are ranked using a 10 -segment Likert scale. This questionnaire survey was taken from May 23 to 29, 2013, using a website. Twelve expert examinees participated in this internet survey, $41.7 \%$ of the examinees were male, and $58.3 \%$ were female. Figure 8 shows that the 21 items have average scores. If the scores are over 8 , they are considered high level items and are selected to conceptualize the new product development. After calculating, the high level scores are selected as shown below (Figure 8). Items related to "comfort," "point in time," and "confidence" rate over 8.4; "reputation" is 8.2; items of "security" and "social" are 8.1; items of "environment," "sense of place," and "independence" each score 8.0.

\subsubsection{The POGs of Creative Design for Caring Transnet} Drivers. In Table 3, we induct those high value items to find the detailed decision for fuzzy front end: (1) Transnet truck needs to pass the narrow streets or alleys, (2) it is easy to drive and needs to be able to charge at any time, and (3) it is collapsible, easy to carry cargo, small electric vehicles, which 

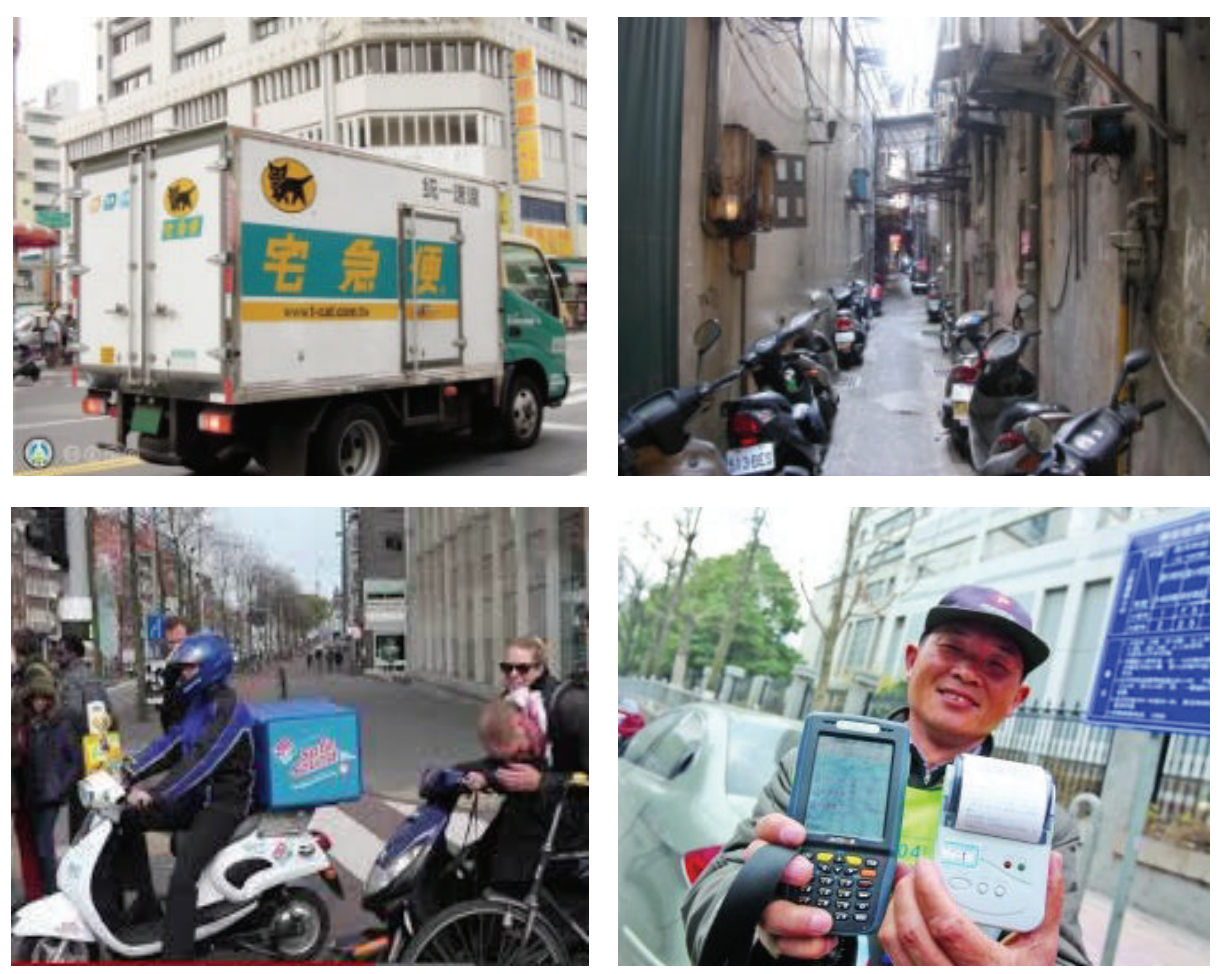

FIGURE 9: The scenario of desirability, usability, and usefulness of Transnet service.

are some design value opportunities for supporting logistic Transnet system.

3.3. Conceptualizing Opportunities. Here we try to conceptualize the proposed design direction and value opportunities and select the empirical data and major items to describe the fuzzy front end of opportunities: imagination of the user scenario and design approach the upper and right quadrant to explain the location of design opportunity.

3.3.1. Focusing on the LEF-Scenario of User Working and Product Environment. Figure 9 shows the popularity of smart devices used for special tasks combined with the commercialization of online shopping for service. Together, these suggest the need to achieve a mechanism for Transnet service. The scenario of the user's working and product environment will be with narrow alleys and crowded cars tide where the user drives a truck for desirable, usable, and useful Transnet service. A new product is needed to solve the problems arising from those situations. It also needs to depend on LEF to construct more clear design direction as following: (1) lifestyle impact: a customized carrier for Transnet drivers, (2) ergonomics: an uninterrupted power vehicle with electrical storage, and (3) feature that must be durable and useful for users and the feature becomes minor issue.

3.3.2. Moving to Upper Right Quadrant: High Style and Technology for Product Design. The upper right quadrant integrates style and technology of product design to make a successful design. Selecting several products located in the

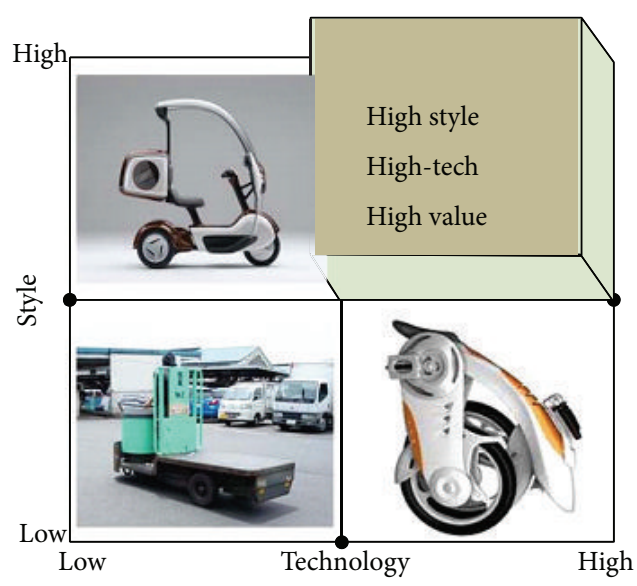

FIGURE 10: The design idea must approach right and upper quadrant and other reference products.

other quadrants shows us the high style, high-tech, and high values for target products to approach the first quadrant, as in Figure 10. Finally, a design idea can be chosen in which a foldable vehicle is used to access urban narrow alleys, with a lock at the side of truck for convenience.

3.4. Realizing Opportunities. From opportunity to conceptualization, value is based on experience and statistics. Using these, we can recognize and identify the fuzzy front end of the design opportunity. We find that a power-driven and easily 


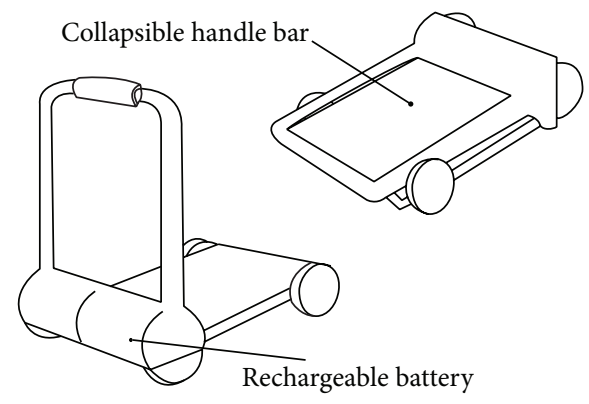

(a)

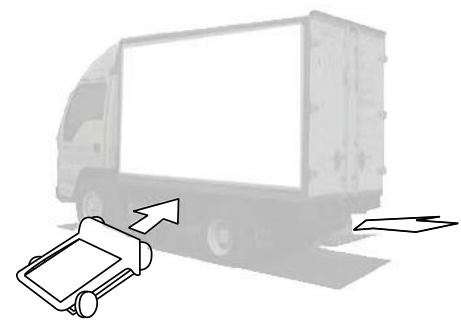

(b)

Figure 11: (a) An initial design idea. (b) Two places for locating carrier from side or rear for final design.

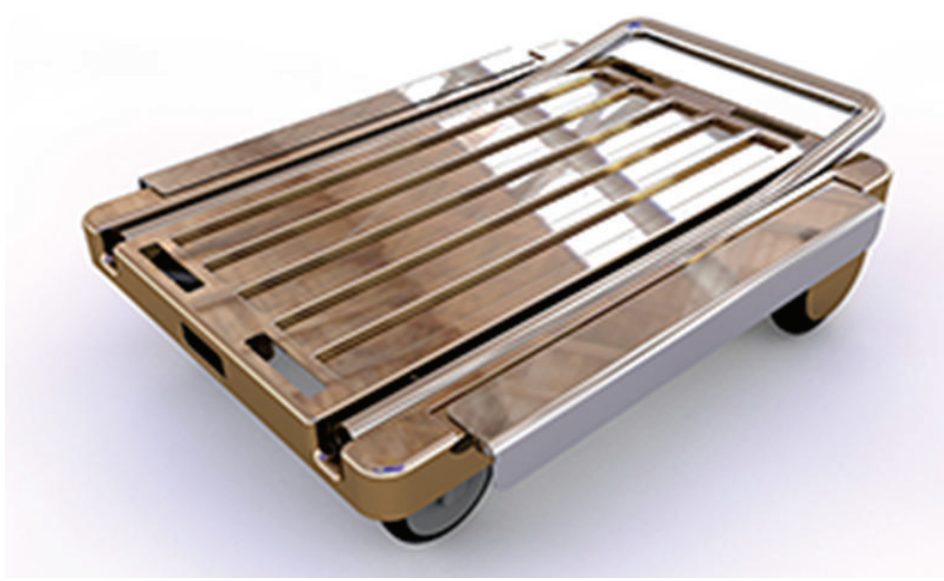

(a)

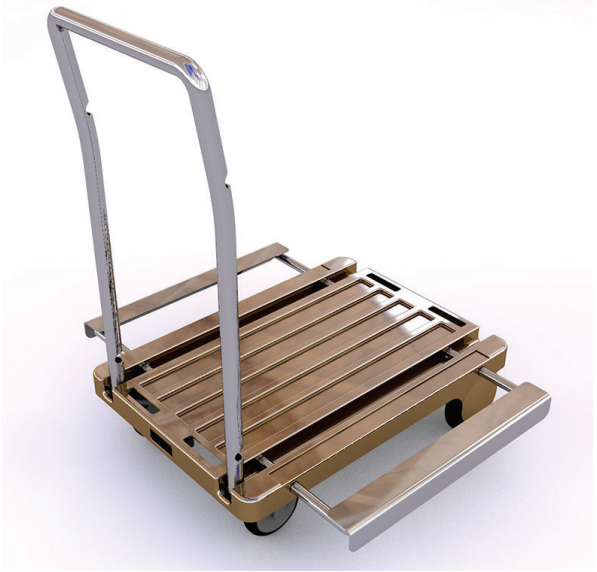

(b)

Figure 12: (a) The final design solution. (b) Operating extended platform.

usable light vehicle which can be loaded on large vehicles will provide better quality Transnet for drivers and customers.

3.4.1. Reconfirming the Design Opportunity from LEF. We can reconfirm this design process for delivery shuttle trucks. It is difficult for drivers to deliver goods to customers because there are still many small and narrow lanes in the city. Although delivery personnel can use a small feeder carrier, they cannot work efficiently. As discussed by the LEF (lifestyle, ergonomics, and feature), a power-driven vehicle can be adapted to drive short distances in urban areas, one which can be charged from a truck on which it can be placed on the side or rear. Such a vehicle can be used for frequent short electric-powered driving without a large rechargeable battery.

\subsubsection{Designing a Light Vehicle for Supporting Truck Driver} on Transnet Service. In order to reduce the volume of the vehicle, the design must be collapsible, the first idea is as Figure 11 and the final proposal is as Figure 12(a), and it is with extendable bar to enlarge the cargo volume, Figure 13(a) shows it is with an auxiliary electric wheel hub motor with battery, Figure 13(b) shows that it can charge from truck. This would be convenient and save space and can be located on the side or rear of Transnet truck where it could be easily picked up and used by the truck's drivers. They could add another carrier to carry more goods as shown in Figure 14.

\section{Conclusion}

This analysis can make the selected SET topics understand their relationship and what the main problem, main target, and connection lines are. To make effort to do some modification, thinking more safe and more space to care driver. The care and design have been constructed as a design issue; it seems to begin from green design, considering humans and the environment to combine motivation [28]. In fact, it can let the design get a chance to be reinforced to fit for living creatures; this design concept can be constructed between carers and by-carers to improve product value and create valuable issues for common topic.

This study proposes an application of ISM to make design direction in the new integrated product development from determining the interrelated strengths on each topic. This synthesized process based on ISM to make it more methodical and logical is easier and less time to achieve a complete design procedure which is possible to be done by designers themselves. The methodology of this study can be applied 


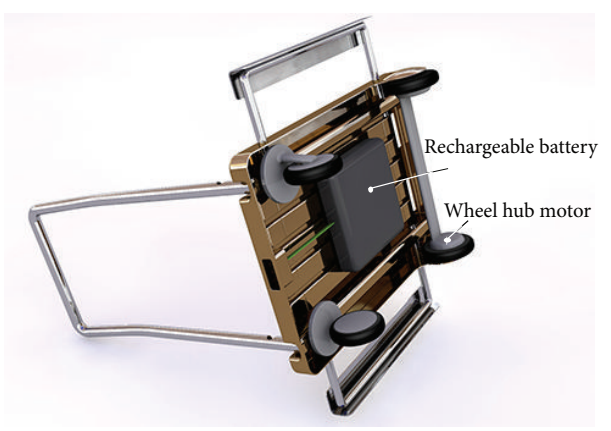

(a)

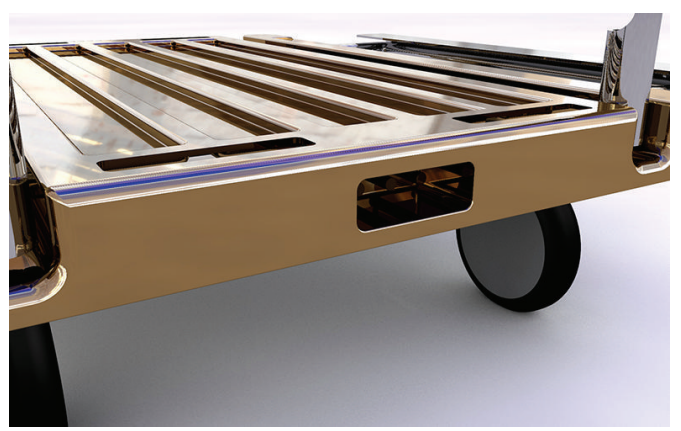

(b)

FIGURE 13: (a) Explaining electric components for light carrier. (b) The charging socket.

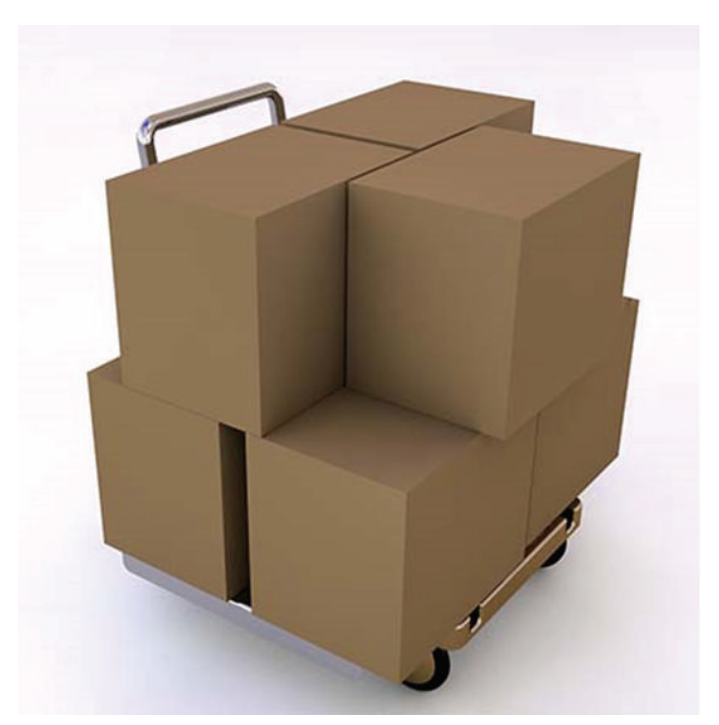

FIGURE 14: The carrying carton possibility.

to the beginning stage of product innovation, particularly in the design process of diverse environmental factors. In addition to developing a suitable product for special needs, it can also be applied to establish new methods. Though a caring design is taken to care for logistic Transnet, the proposed method can generally be applied to overlap of disciplines leading to value for user centered design research. Finally, it is responsible for the process of iNPD to propose a light electric vehicle for city logistic Transnet. An electric folding vehicle has excellent maneuverability in narrow alleys in the downtown area, combined with the concept for logistics services. Such a vehicle will increase service efficiency and decrease manpower cost. A power-driven vehicle can be adapted to drive short distances in urban areas, one which can be charged from a truck on which it can be placed on the side or rear. It owns elastic extending platform to increase space carrying light and big cargo. There is an auxiliary electric wheel hub motor with battery under platform and standup space for riding if the platform space is broader enough, therefore, we can imagine this light electric folding vehicle has excellent maneuverability in narrow alleys, the electric power and broader carrier vehicle can increase service efficiency and decrease manpower cost.

\section{Conflict of Interests}

The authors declare that there is no conflict of interests regarding the publication of this paper.

\section{References}

[1] J. Cagan and M. C. Vogel, Creating Breakthrough Products: Revealing the Secrets That Drive Global Innovation, Pearson Education, 2013.

[2] J. Cagan and M. C. Vogel, Breakthrough Products: Innovation from Product Planning to Program Approval, Pearson Education, Upper Saddle River, NJ, USA, 2002.

[3] T. Metzler and K. Shea, "Lessons learned from a project-based learning approach for teaching new cognitive product development to multi-disciplinary student teams," in Proceedings of the ASME 2011 International Design Engineering Technical Conferences and Computers and Information in Engineering Conference (IDETC/CIE '11), pp. 589-598, Washington, DC, USA, August 2011.

[4] M. T. Wang, R. Chen, J. Y. Lin, and C. T. Wu, "The research of creative design of green equipment for caring outdoor activities," in Proceedings of the 3rd International Asia Conference on Industrial Engineering and Management Innovation, pp. 207211, Tsinghua University, Beijing, China, August 2012.

[5] L. Xu, G. H. Zong, and R. Zhang, "The research and application of industrial design method based on iNPD," Journal of Engineering Graphics, vol. 4, pp. 130-139, 2010.

[6] P. Rothstein, Closing the Gap between Practice and Education: A Case Study, Arizona State University, Phoenix, Ariz, USA, 2002.

[7] J. Clarkson and C. Eckert, "Design process improvement: a review of current practice," in Integrated New Product Development, J. Cagan and C. M. Vogel, Eds., pp. 389-403, Springer, 2005.

[8] M. T. Wang, R. Chen, J. Y. Lin, and C. T. Wu, "The research of creative design of green equipment for caring outdoor activities," in Proceedings of the 3rd International Asia Conference on Industrial Engineering and Management Innovation, pp. 207211, Tsinghua University, Beijing, China, August 2012.

[9] I. Akman and A. Mishra, "Gender, age and income differences in internet usage among employees in organizations," Computers in Human Behavior, vol. 26, no. 3, pp. 482-490, 2010. 
[10] E. Tazki and M. Amagsa, Fuzzy Sets and Systems: Structural Modeling in a Class of Systems Using Fuzzy Sets Theory, NorthHolland, New York, NY, USA, 1997.

[11] J. N. Warfield, An Assault on Complexity, Battelle Monographs, Battelle Memorial Institute, Columbus, Ohio, USA, 1973.

[12] J. N. Warfield, "Toward interpretation of complex structural models," IEEE Transactions on Systems, Man, and Cybernetics, vol. 4, no. 5, pp. 405-417, 1974.

[13] J. N. Warfield, Social Systems: Planning, Policy and Complexity, John Wiley \& Sons, New York, NY, USA, 1976.

[14] J. N. Warfield, "Implication structures for system interconnection matrices," IEEE Transactions on Systems, Man, and Cybernetics, vol. 6, no. 1, pp. 18-24, 1976.

[15] F. Harary, R. Z. Norman, and D. Cartwright, Structural Models: An Introduction to the Theory of Directed Graphs, John Wiley \& Sons, New York, NY, USA, 1965.

[16] R. Attri, N. Dev, and V. Sharma, "Interpretive Structural Modelling (ISM) approach: an overview," Research Journal of Management Sciences, vol. 2, no. 2, pp. 3-8, 2013.

[17] A. P. Sage, Interpretive Structural Modelling: Methodology for Large-Scale Systems, McGraw-Hill, New York, NY, USA, 1977.

[18] A. Agarwal, R. Shankar, and M. K. Tiwari, "Modeling agility of supply chain," Industrial Marketing Management, vol. 36, no. 4, pp. 443-457, 2007.

[19] M. N. Faisal, D. K. Banwet, and R. Shankar, "Supply chain risk mitigation: modeling the enablers," Business Process Management Journal, vol. 12, no. 4, pp. 535-552, 2006.

[20] D. W. Malone, "An Introduction to the Application of interpretive Structural Modeling," Proceedings of the IEEE, vol. 63, no. 3 , pp. 397-404, 1975.

[21] W.-M. Wang, A. H. I. Lee, L.-P. Peng, and Z.-L. Wu, "An integrated decision making model for district revitalization and regeneration project selection," Decision Support Systems, vol. 54, no. 2, pp. 1092-1103, 2013.

[22] A. H. I. Lee, M.-C. Hung, H.-Y. Kang, and W. L. Pearn, "A wind turbine evaluation model under a multi-criteria decision making environment," Energy Conversion and Management, vol. 64, pp. 289-300, 2012.

[23] Y.-C. Lee, Y. H. Chao, and S.-B. Lin, "Structural approach to design user interface," Computers in Industry, vol. 61, no. 7, pp. 613-623, 2010.

[24] S.-W. Hsiao and E. Liu, "A structural component-based approach for designing product family," Computers in Industry, vol. 56, no. 1, pp. 13-28, 2005.

[25] S.-W. Hsiao, Y.-C. Ko, C.-H. Lo, and S.-H. Chen, "An ISM, DEI, and ANP based approach for product family development," Advanced Engineering Informatics, vol. 27, no. 1, pp. 131-148, 2013.

[26] S. Jharkharia and R. Shankar, "IT enablement of supply chains: modelling the enablers," International Journal of Productivity and Performance Management, vol. 53, no. 8, pp. 700-712, 2004.

[27] N. Noddings, Caring: A Feminine Approach to Ethics and Moral Education, University of California Press, Berkeley, Calif, USA, 2002.

[28] M. T. Wang, "The investigation of design concept on apple products from Bandura's reciprocal determinism," in Proceedings of the Academic Research Chinese Institute of Design Symposium, p. D-13, I-Shou University, Kaohsiung, Taiwan, May 2013.

[29] J. N. Warfield, A Science of Generic Design: Managing Complexity through System Design, Iowa State University Press, 1994. 


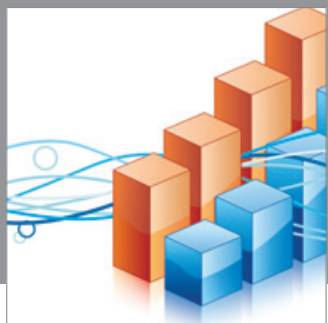

Advances in

Operations Research

mansans

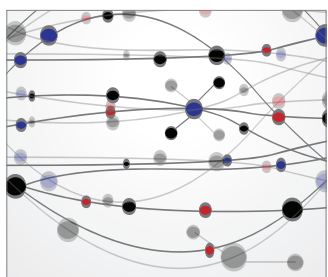

The Scientific World Journal
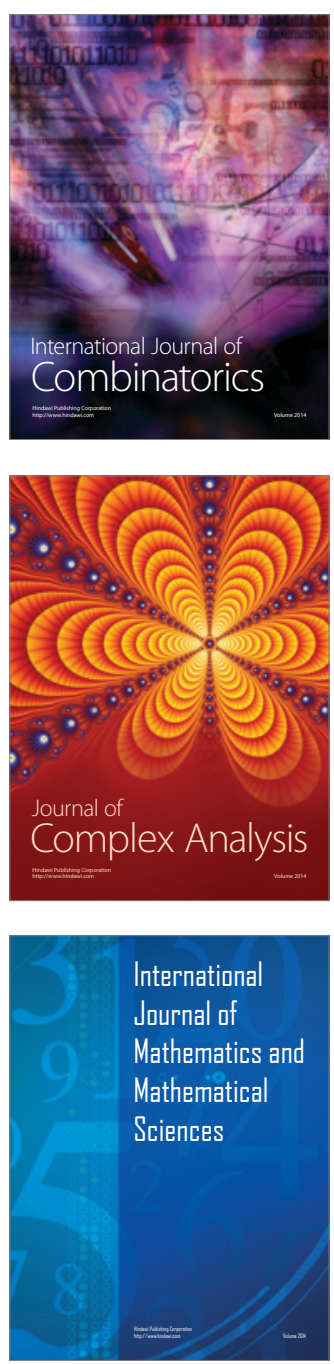
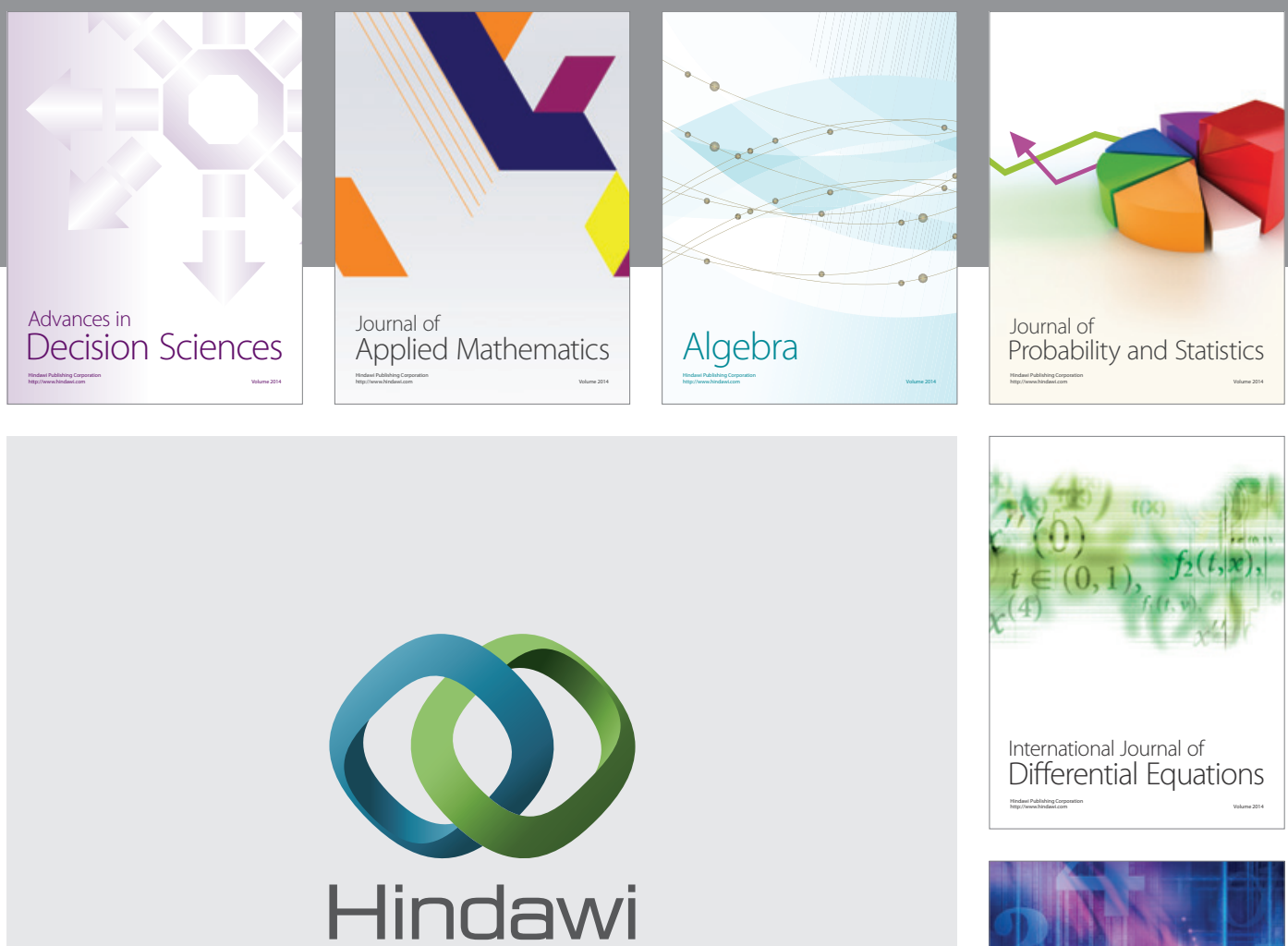

Submit your manuscripts at http://www.hindawi.com
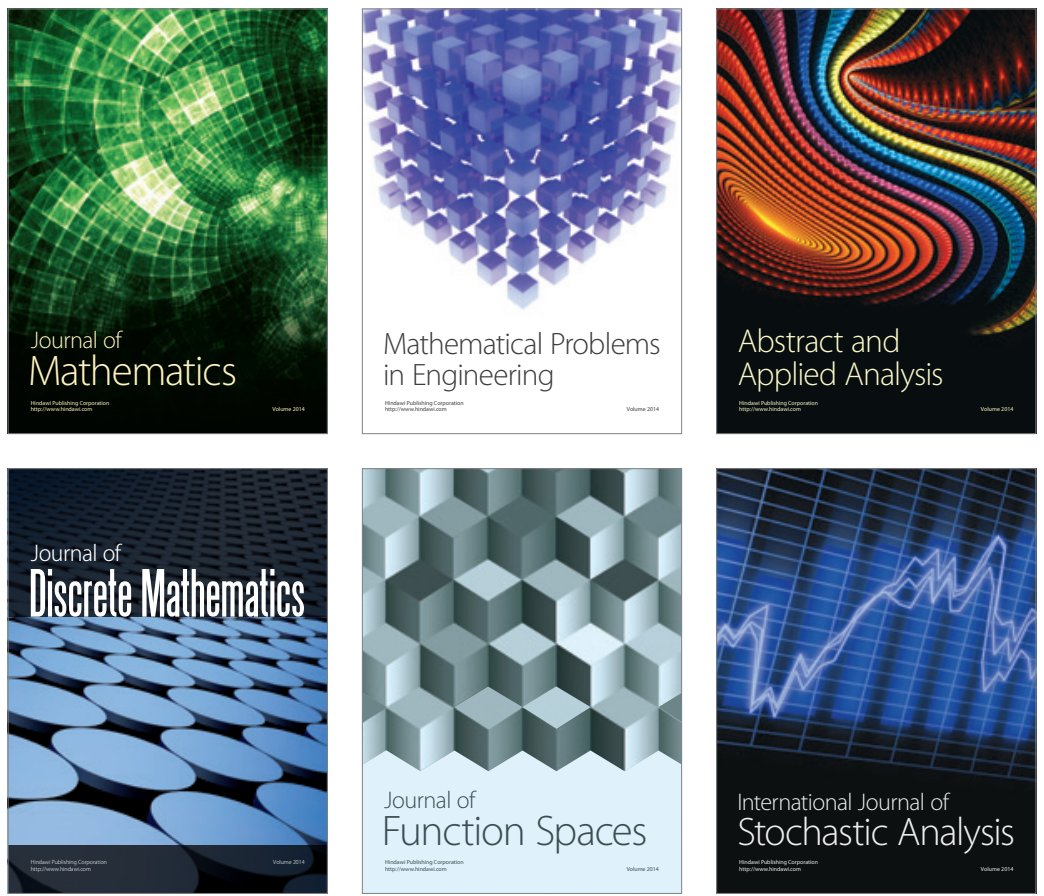

Journal of

Function Spaces

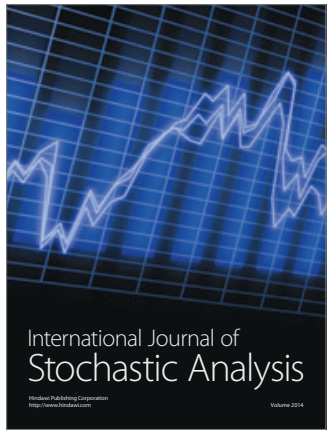

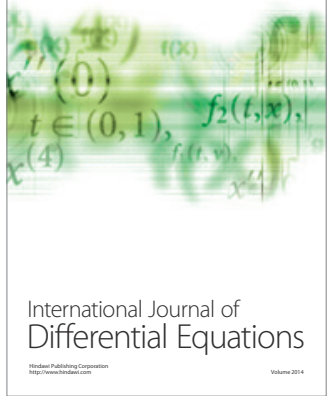
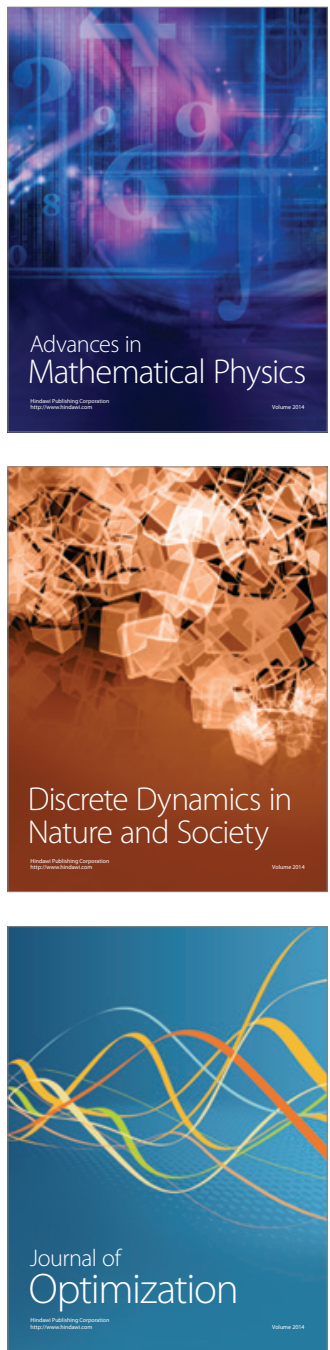